\title{
Cup feeding: an alternative method of infant feeding
}

\author{
Sandra Lang, Clive J Lawrence, Richard L'E Orme
}

Artificial methods of infant feeding, ranging from pap bowls, feeding horns, cups with lips, and spouts and bottles have existed since prehistoric times. ${ }^{1}$ Though many of these feeding vessels have now completely disappeared, the bottle and teat have so dominated western thinking in recent years that the use of other artificial methods of infant feeding has been largely overlooked.

During four years in Nepal with Voluntary Service Overseas one of the authors (SL) observed mothers cup feeding low birthweight infants with freshly expressed breast milk, using either a cupped hand or a small metal or glass tumbler. Cup feeding is used in several developing countries, not only by mothers ${ }^{2}$ who have limited access to hospital facilities but also by paediatric and special care baby units. $^{3-8}$ Its primary and most important use is to provide a safe artificial method of feeding preterm and low birthweight infants until they are strong and/or mature enough to be fully breast fed. The other important function of cup feeding in these countries is to prevent the use of bottle feeding, which is known to result in increased infant morbidity and mortality, ${ }^{9}$ particularly where hygiene is a problem, ${ }^{2}$ the sterilisation of bottles difficult, and gastric tubes not easily available. In such an environment cups provide a simple, practical, and inexpensive method of feeding. ${ }^{10}$

Experience in the developing world and in several European neonatal ${ }^{11} 12$ and transitional care units ${ }^{13}$ indicates that cup feeding is a skill easily acquired by preterm infants, at a stage before efficient breast or bottle feeding is possible, and at a point in development when up to now it has been generally assumed that gastric tubes are a necessity. ${ }^{14} 15$ According to standard medical and nursing paediatric texts, 'oral' feeding cannot be successfully started until an infant is able to coordinate its suck, swallow and breathing reflexes, which usually occurs between 32 and 35 weeks' gestation. ${ }^{1617}$ As a result gastric tubes are commonly used in British neonatal units throughout the period of transition to breast or bottle feeding, and are usually the only feeding method available for well, preterm infants of less than 32 weeks' gestation. Infants of more than 32 weeks' gestation may also receive gastric tube feeds, but those who are to be breast fed, in addition commonly receive supplementary bottle feeds, particularly at night. and when mothers are absent. This may not be in accordance with the mothers' wishes but there are few choices open either to staff or parents for an unsettled infant, when gastric tube feeding does not satisfy the infant's psychological and social needs, and the mother is not available to breast feed. Experience in the Exeter neonatal unit has clearly shown that cup feeding in these circumstances can provide a very acceptable alternative.

Although little research has been carried out to determine whether bottle feeding interferes with a term infant's ability to breast feed successfully, several authors have drawn attention to the difference between the sucking techniques of breast and bottle feeding. ${ }^{18-22}$ To breast feed successfully the infant has to open its mouth widely to accommodate the breast tissue, and protrude its tongue over the bottom lip, which is curled outwards under the areola. In bottle feeding the infant sucks on the teat with a partially closed mouth. When this latter sucking action is used by infants at the breast it can lead to sore nipples, a diminished milk supply, and the cessation of breast feeding. Both bottle teats and pacifiers (dummies) 22 encourage this sucking technique, which may affect the eventual success of healthy term infants being able to establish breast feeding. Unfortunately there is no way of predicting which infants will develop problems with breast feeding as a result of learning these two different sucking techniques. Because the establishment of breast feeding in a sick or preterm infant is less straightforward than in a term infant, a method of feeding which does not lead to inappropriate sucking techniques is highly desirable.

\section{Cup feeding in Exeter}

In this paper we define cup feeding as a method of feeding milk to an infant from a small polypropylene or glass tumbler without a spout or lip (see figure).

In Exeter, infants from 30 weeks' postconceptional age at the time of the first cup feed have demonstrated their ability to coordinate their tongue movements, to swallow, and to breathe without difficulty while cup feeding.
Health, Royal Devc R L'E Orme

Correspondence to: Dr Lawrence. 


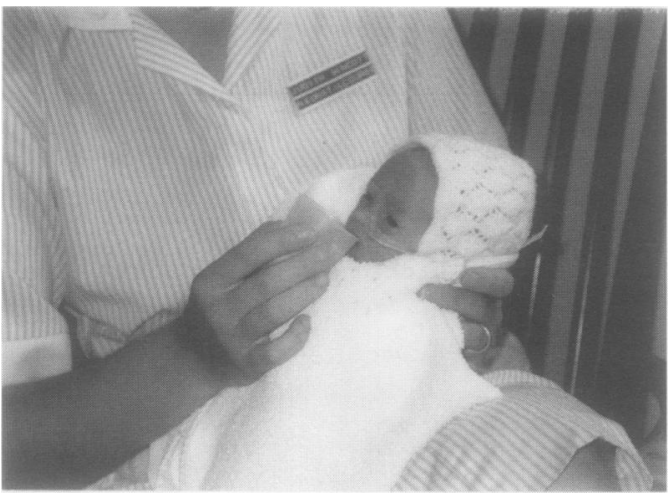

Baby being cup fed.

Their technique is, however, subtly different to that of more mature infants. The cup is tilted so that the milk just touches the infant's lips. The initial sensory stimulation therefore, is through the infant's lips and possibly also through the olfactory nerves. This is usually followed by observable tongue activity, particularly in infants of 30-34 weeks' gestation. These infants 'lap' by protruding their tongue into the milk to obtain small boluses, which are often then held in their mouth for some time before swallowing. As the infant matures 'lapping' becomes less obvious and a 'sipping' action develops. Tongue action is vital for successful breast feeding, because the ability to extend the tongue is essential for efficient 'stripping' of the milk ducts. ${ }^{23}$ During cup feeding, particularly when breast milk is used, a range of facial expressions are frequently observed that include 'blinking', 'smiling', and 'frowning'. It is also a common reaction when the cup is prematurely withdrawn for an infant to protrude its tongue and actively 'look' for the milk, even though the lip stimulus has been removed. These reactions are also more apparent in infants of 30-34 weeks' postconceptional age.

In the Exeter neonatal unit more than $\mathbf{5 0 0}$ infants have received cup feeds on one or more occasions since 1989. It was initially introduced to the unit for breast fed infants nearing discharge, whose mothers were unable to be present for each feed; and, secondly, as an additional method of feeding preterm infants intended to be breast fed, but who were not satisfied orally by gastric tube feeds, or in whom the staff found the development of inappropriate sucking patterns.

Cup feeding was introduced gradually over the first year. This was because of experience in the Kenyatta National Hospital in Nairobi, where inadequate preparation had resulted in staff opposition. ${ }^{3}$ It was equally important to proceed slowly because at that time no precedent existed for its use in neonatal units in the UK. This was despite the fact that it is a method recommended for use with sick and low birthweight infants in World Health Organisation and Unicef publications, 2425 including those relating to the baby friendly hospital initiative. ${ }^{25}$ It is also a feeding technique familiar to health professionals with experience in developing countries. ${ }^{8}$

By the end of the first year it was apparent that cup feeding was appropriate for six groups of infants. These were:

(1) Infants nearing discharge who were already established on the breast but whose mothers were not resident on the unit.

(2) Preterm infants, who were to be breast fed but who would not settle after gastric tube feeds. These included infants who were awake and alert when a feed was due, but who were either too immature to breast feed or unable to complete a breast feed, or whose mothers were not present at the time of a feed.

(3) Infants with a cleft lip and/or palate whose mothers wished to establish breast feeding, but who were also likely to require an additional method of feeding until surgical repair of the defect was completed.

(4) Infants with an uncoordinated suck, swallow, and breathing pattern caused by asphyxia or some other neurological condition that interfered with the successful establishment of breast or bottle feeding.

(5) Infants born by caesarean section, if breast feeding was not possible within the first few hours of surgery, or whose mothers were initially unwell but who intended to breast feed.

(6) Term or preterm infants at discharge who became tired before they were able to complete a breast feed.

Cup feeding was introduced either immediately after admission or as soon as the infant was able to tolerate two to three hourly bolus feeds by gastric tube. Removal of the tube occurred once the infant could take at least three successive cup feeds, the combined volumes of which were considered to be satisfactory by the unit staff. Otherwise a cup was used intermittently with the gastric tube until the infant was able to go to the breast successfully on three or more occasions a day. Cup feeding was not used whenever breast feeding was possible.

Two studies undertaken since 1989 have collected data on more than 80 cup fed infants, involving over 800 episodes of cup feeding. The first of these, a prospective study examining the feeding and growth patterns of 600 infants included the first 65 infants to be cup fed. The second more recent study examined the variation in nutritional content of breast milk depending on the method of expression and included 20 infants who received some of their mothers expressed breast milk by cup.

In these studies cup feeding was used according to the infants needs and in situations where previously a health professional would have introduced a bottle. The following results therefore, are not part of an organised trial of cup feeding.

Ethical approval for both studies was given by the Exeter Health Authority.

\section{Summary data}

A summary comparison of the 85 infants in the two studies, for four gestational age groups $(<28,29-31,32-36$, and $>37$ weeks), is provided in the table. It is evident that regardless of gestational age at birth, cup feeding is 
Summary statistics, median (with lower quartile - upper quartile) for the 85 cup fed infants

\begin{tabular}{cclllll}
\hline $\begin{array}{l}\text { Gestational } \\
\text { age (weeks) }\end{array}$ & $\begin{array}{l}\text { No of } \\
\text { cases }\end{array}$ & $\begin{array}{l}\text { Age at first cup fed } \\
\text { (weeks/days) }\end{array}$ & $\begin{array}{l}\text { Age at first breast feed } \\
\text { (weeks/days) }\end{array}$ & $\begin{array}{l}\text { Age at discharge } \\
\text { (weeks/days) }\end{array}$ & $\begin{array}{l}\text { Total days } \\
\text { cup fed }\end{array}$ & $\begin{array}{l}\text { Breast feeding at } \\
\text { discharge (\%) }\end{array}$ \\
\hline$<28$ & 6 & $35 / 4(31 / 6-36 / 3)$ & $33 / 5(31 / 1-36 / 0)$ & $41 / 0(36 / 3-44 / 1)$ & $10 \cdot 7(9-12)$ & 67 \\
$29-31$ & 9 & $32 / 2(30 / 5-32 / 5)$ & $31 / 5(31 / 2-31 / 6)$ & $35 / 1(34 / 1-36 / 1)$ & $8 \cdot 0(2-14)$ & 89 \\
$32-36$ & 39 & $35 / 2(38 / 4-40 / 5)$ & $34 / 3(34 / 1-36 / 1)$ & $36 / 3(36 / 0-37 / 4)$ & $4 \cdot 0(2-11)$ & 77 \\
$>37$ & 31 & $39 / 5(38 / 4-40 / 5)$ & $40 / 1(38 / 2-40 / 3)$ & $40 / 4(39 / 1-42 / 0)$ & $2 \cdot 0(1-4)$ & 77 \\
\hline
\end{tabular}

possible once the infant has reached 30 weeks' postconceptional age. At this stage it is usual for the infant to take a comparatively small volume, $5-15 \mathrm{ml}$. Within a very short period of time, however, infants would take the full amount prescribed and frequently substantially more. Initially one cup per day was offered and thereafter the infant would be offered the cup on demand.

Infants of 28 weeks' gestation and less at birth usually require ventilatory assistance, which may delay oral feeding. In the table it can be seen that the six infants in this group, compared with those born between 29 and 31 weeks' gestation, began cup feeding far later (at around the age of 35 weeks' postconceptional age) and were also discharged much later. For many of the infants born very prematurely the initial attempt at the breast took place before the first cup feed. This is because the aim of cup feeding is solely to provide an alternative nutritive method of feeding where breast feeding is not possible. Breast feeding, on the other hand also encourages skin-toskin contact between mother and infant, familiarises the infant with the breast, and allows the infant to taste a little breast milk hand expressed onto the nipple.

In the initial eight months of the first study eight infants were given cup feeds and in the remaining seven month period 58 infants received cup feeds. In the early months of the study it was common practice to give supplementary bottles to infants who were to breast feed, including cup fed infants. As cup feeding became more established this practice became unnecessary.

Forty of the 58 infants received no bottles during their period in hospital. Of these 40 infants, 36 were discharged exclusively breast feeding $(90 \%)$, that is, they received all their nutritional needs from the breast. Of the remaining four infants, two were discharged cup/breast feeding and two were transferred to other units cup and tube feeding. Of the 18 infants who received both bottle and breast feeding only nine $(50 \%)$ succeeded in establishing breast feeding by the time of discharge - six infants were discharged breast and bottle feeding, all of whom had discontinued breast feeding within six weeks.

Of the 84 cup feeding mothers in the two studies $76(90 \%)$ intended to breast feed. At discharge, 62 of the $76(81 \%)$ mothers were exclusively breast feeding; four mothers $(5 \%)$ had changed to bottle feeding; six $(8 \%)$ were both breast and bottle feeding; two $(3 \%)$ were cup and breast feeding; and two (3\%) were using other methods. This pattern can be compared with a group of mothers who intended to breast feed and whose infants were not cup fed. There were 365 mothers (372 infants) in this group. At discharge, 231 (63\%) mothers were exclusively breast feeding; 60 mothers $(17 \%)$ had changed to bottle feeding; $33(9 \%)$ were both breast and bottle feeding; and the remaining $41(11 \%)$ were transferred to other units while still fed by gastric tube. The mothers of the two groups were comparable with respect to age, parity and social status, and the infants similar with respect to gestational age and condition at birth. The only major difference between the two groups was in the method of feeding, which strongly suggests that cup feeding can contribute to the establishment of successful breast feeding.

Without conducting a fully controlled and randomised trial it is not possible to make claims of earlier establishment of breast feeding through the use of cups, or to state precisely the extent to which they lessen the use of gastric tubes. Nevertheless, we believe that where cup feeds have been given, gastric tube feeds or bottles would previously have been used in their place.

\section{Uses of cup feeding in special circumstances}

There is also little published work to demonstrate the use of cup feeding in infants with particular feeding problems. We offer the following two case studies as examples.

One infant was born at 26 weeks' gestation and had Apgar scores of 1,2, and 5 at 1, 5, and 10 minutes with severe birth asphyxia. He was able to be discharged at 40 weeks' gestation cup feeding, though still unable to bottle feed. At the age of 9 months ( 6 months adjusted age) he had been weaned off the cup onto the bottle. His mother was happy with the method of feeding, and developed a close and easy relationship with her son. It is doubtful whether long term tube feeding, in hospital or at home, would have allowed bonding to develop in such an agreeable way.

A girl was born at term with unilateral cleft lip and palate; her father also had a cleft lip and palate. His wife was initially determined to breast feed, but both parents realised an additional method of feeding was likely to be required. The father was taught to cup feed within the first 48 hours. In the circumstances it was important to involve him as early as possible, without compromising the mother's wishes to breast feed. The infant was able to feed well from a cup, which gave the mother time to try to establish breast feeding without being pressurised into introducing a bottle.

The policy of discharging preterm infants cup and breast feeding rather than tube feeding (when appropriate) has been implemented in North Staffordshire neonatal unit. A recently published audit has shown that cup feeding 
along with other changes to their breast feeding policy has also resulted in a dramatic increase in mothers breast feeding at discharge. ${ }^{12} \mathrm{~A}$ study in France also concluded that cup feeding low birthweight infants reduced both the length of time that gastric tubes were necessary, and also the number of admissions to the neonatal unit. ${ }^{13}$

\section{Discussion}

In situations where an alternative to bottle and gastric tube feeding is required, cup feeding provides a simple, practical, and effective solution. If offers several potential benefits. It is non-invasive, thus any real or theoretical possibility of sucking confusion is avoided because the infant does not have to cope with a nipple or teat in its mouth. The infant can pace its own intake as long as the cup is held so that the milk is just touching the infant's lips and not poured into its mouth. Furthermore, as the pace of lapping/sipping is dependent on the infant itself, respiration is easier to control, and swallowing occurs when the infant is ready. As a result very little energy is required. Infants as young as 30 weeks were observed to be capable of maintaining heart rate, respirations, and satisfactory oxygen saturation while cup feeding.

For infants with a problem of uncoordinated sucking or who cannot cope with a nipple/teat and a bolus of milk at the same time, it is beneficial to have an alternative oral method of feeding that encourages a controlled use of the tongue while allowing feeding to take place at the infant's own pace. It has also been suggested that there may be a relationship between abnormal infant feeding and later speech development. Selley et al have identified seven common factors in 'co-ordinated neonatal feeding and speech production', namely rhythm, breath control, lip tone, delicate tongue movements, speed of muscle movements, well developed sensory feedback systems, and a relaxed feeding situation. ${ }^{26} \mathrm{Cup}$ feeding appears to encourage the development and maturation of these factors, which we have observed in sequential observations of preterm infants from 30 to 35 weeks' gestation. Positive early feeding experiences may therefore have important consequences for those infants who require further specialist help and are at risk of developing long term speech and feeding problems. It may also be important to provide a positive oral experience to an infant who has been intubated, experienced frequent nasal/ oral suctioning, had an oral plate in its mouth, ${ }^{27}$ or has been fed by nasal or oral gastric tubes.

Cup feeding is a simple method of feeding that encourages the involvement of both parents at a stage when oral feeding is not normally considered possible. The fostering of early positive body and eye contact between parents and their infant is essential, particularly when the infant may have suffered discomfort, isolation, and possibly pain in its early life. Parents need to be helped and encouraged to 'nurture' their infant, and not to view feeding simply in terms of nutrition. It cannot be overemphasised, therefore, how important it is for parents to be given control of their infant's feeding as soon as is feasible. This helps to ameliorate what can be for them, a very abnormal situation in terms of parental expectations of the outcome of pregnancy.

Oral feeding is important physiologically. The effect of pancreatic lipases are considered to be minimal in an infant. The lingual lipases therefore, are vital to the breakdown of dietary triglycerides. ${ }^{28-30}$ Though the amounts of breast milk taken initially may be small they are able to prime the oral phase of digestion. The total volume of milk taken may vary from feed to feed. Because the infant controls the amount taken, it may exceed that prescribed on the fluid chart. Whether this also correlates with the energy content of the milk is not known. It is significant, however, that vomiting is unusual after cup feeding regardless of the quantity taken.

To introduce an unfamiliar procedure into a neonatal unit is undoubtedly a challenge, particularly if it is seen as time consuming. Our experience, however, suggests that the time taken in cup feeding can vary as widely as the time taken for bottle or tube feeding, and by teaching the skill to parents, health professionals are free to attend to other tasks. ${ }^{11}$ Helping a mother and infant to establish breast feeding in a neonatal unit is also not a quick or easy task and any safe measure that will contribute to a successful outcome should be used. Cup feeding is one such measure, which in addition allows the introduction of a 'nobottle' policy where appropriate.

Cup feeding is an alternative method of feeding that broadens the options available to both parents and health professionals, who may require unconventional solutions to difficult feeding situations. Cup feeding should be seriously considered for use in neonatal and transitional care units.

\section{Current and future research into cup feeding}

Two further trials of cup feeding are currently taking place. In Switzerland a multicentre trial is underway examining the cup as an alternative to bottle feeding for supplementary. feeding of term infants, and in Sweden, a trial in the Karolinska Hospital is looking at the feasibility of cup feeding hypoglycaemic infants rather than using bottles. In addition a research team in Canada, possibly with British collaboration, is planning a multicentre randomised controlled trial of cup feeding in neonatal units to start in 1995.

1 Fildes V. Artificial feeding, feeding vessels, the evidence from artefacts and art. Breasts, bottles and babies. Edinburgh: Edinburgh University Press, 1986: 307-42. 2 Ashraf RN, Jalil F, Khan SR, et al. Early child health in Lahore, Pakistan: V. Feeding patterns. Acta Paediat Scand 1993; 390 (suppl): 47-81.

3 Musoke RN. Breastfeeding promotion: feeding the low birth weight infant. Int $\mathcal{F}$ Gynaecol Obstet 1990; 31 (supp 1): 57-9.

4 Armstrong HC. Breastfeeding low birthweight babies: advances in Kenya. Fournal of Human Lactation 1987; 3: 2 
5 Muhudhia SO, Musoke RN. Postnatal weight gain of exclusively breast fed preterm African infants. $₹$ Trop Pediatr sively breast fed

6 Minchin M. Premature babies: why breast is best. New Generation 1987; Sept: 36-7.

7 Newman J. Breastfeeding problems associated with the early introduction of bottles and pacifiers. Foumal of Huma Lactation 1990; 6: 59-63.

8 Shallow HED. Cup-feeding - an alternative method [Letter]. Midwives Chronicle and Nursing Notes 1994; 107: 292.

9 World Health Organisation. The infant and young child during periods of acute infection. In: Akre J, ed. Infant feeding: the physiological basis. WHO Bulletin 1989;67 feeding: the physio
(suppl): 85-95.

10 Armstrong $\mathrm{H}$. Are feeding bottles ever needed? Breastfeeding briefs. Geneva: Geneva Infant Feeding Association (member of The International Baby Food Action Network), 1986.

11 Moody J. A revolution in baby feeding. New Generation $1993 ; 12(2): 9$

12 Jones E. Breastfeeding in the preterm infant. Modern Midwife 1994; 4 (1): 22-6.

13 Giroux JD, Sizun J, Alix D. L'alimentation à la tasse chez le nouveau-né. Arch Fr Pediatr 1991; 48: 737-40.

14 Steer PA, Lucas A, Sinclair JC. Feeding the low birthweight infant. In: Sinclair JC, Bracken M, eds. Effective care of the newborm infant. Oxford: Oxford University Press, 1992: newborn $125-30$.

15 Lemons P, Stuart M, Lemons JA. Breast-feeding the premature infant. In: Periera GR, ed. Clinics in perinatology and perinatal nutrition. Philadelphia: WB Saunders, 1986 111-22.

16 Burman D. Nutrition in early childhood. In: McLaren D, Burman D, eds. Textbook of paediatric nutrition. London: Churchill Livingstone, 1982: 39-72.

17 Sehgal SK, Prakash O, Gupta A, Mohan M, Anand NK
Evaluation of beneficial effects of nonnutritive sucking in preterm infants. Indian Pediatr 1990; 27: 263-6.

18 Fisher C. Breastfeeding, a midwife's view. fournal of Maternal and Child Health 1981; 652-7.

19 Woolridge MW. The 'anatomy' of infant sucking. Midwifery 1986; 2: 164-5

20 Ardran GM, Kemp FH, Lind JA. Cineradiographic study of bottle feeding. Br F Radiol 1958; 31: 11-22.

21 Ardran GM, Kemp FH, Lind JA. Cineradiographic study of breastfeeding. Br $\mathcal{F}$ Radiol 1958; 31: 156-62.

22 Righard L, Alade MO. Sucking technique and its effect on success of breastfeeding. Birth 1992; 19: 185-9.
suct

23 Royal College of Midwives. Understanding how a baby breastfeeds. Successful breastfeeding. 2nd Ed. London: Churchill Livingstone, 1991: 1-9.

24 WHO/Unicef. Breastfeeding counselling: a training course. Geneva: WHO, 1993.

25 Unicef. Breastfeeding management and promotion in a babyfriendly hospital: an 18-hour course for maternity staff. New York: Unicef, 1993

26 Selley WG, Ellis RE, Flack FC, Brooks WA. Coordination of sucking, swallowing and breathing in the newborn: Its relationship to infant feeding and normal development. British fournal of Disorders of Communication 1990; 25: 311-27.

27 Leach G. Dental plates for oral feeding. Nursing Times 1991; 87 (46): 58-9.

28 Smith LJ, Kaminsky S, D'Souza SW. Neonatal fat digestion and lingual lipase. Acta Paediatr Scand 1986; 75: 913-8.

29 Hamosh M. Lipid metabolism in premature infants energy metabolism, nutrition and growth in premature infants. Biol Neonate 1987; 52 (suppl): 50-64

30 Hamosh M. Lingual and breast milk lipases. Advanced pediatrics year book. Chicago: Year Book Medical Publishers, 1982; 29: 33-67. 